\title{
A Prospective, Multicentre, Single Arm Clinical Study to Evaluate the Effect of Saroglitazar on Non High-Density Lipoprotein Cholesterol in Patients with Diabetic Dyslipidemia Inadequately Controlled with Diet, Exercise, and Statin- The GLIDDER Study
}

\author{
Upendra Kaul ${ }^{1}$, Priyadarshini Arambam ${ }^{1,2}$, Ranjan Kachru ${ }^{3}$, Vineet Bhatia ${ }^{4}$, Yumnam Diana ${ }^{1}$, \\ Nungshijungla ${ }^{5}$, Mitesh Shah ${ }^{6}$, Krupi Parmar ${ }^{6}$, Ashok Jaiswal ${ }^{7}$ and Peeyush Jain ${ }^{5}$ \\ ${ }^{1}$ Batra Hospital and Medical Research Centre, New Delhi, India; ${ }^{2}$ Amity Institute of Public Health, Amity University, Noida, UP, \\ India; ${ }^{3}$ Fortis Flt.Lt. Rajan Dhall Hospital, Vasant Kunj, New Delhi, India; ${ }^{4}$ Fortis Hospital Noida, Gautam Budhh Nagar, Noida, \\ Uttar Pradesh, India; ${ }^{5}$ Fortis Escorts Heart Institute, Okhla Road, New Delhi, India; ${ }^{6}$ Zydus Research Centre, Cadila Healthcare \\ Limited, Ahmedabad, India; ${ }^{7}$ Cadila Healthcare Limited, Ahmedabad, India
}

\begin{abstract}
Objective: Diabetic dyslipidemia is highly atherogenic as it is associated with high triglyceride (TG), high small dense low-density lipoprotein (sd-LDL) particles and low High-Density Lipoprotein Cholesterol (HDL-C). Saroglitazar, a dual peroxisome proliferator activated receptor agonist (predominant PPAR- $\alpha$ agonist and modest PPAR- $\gamma$ agonist), is approved in India for the management of diabetic dyslipidemia. The GLIDDER study was done to evaluate the effects of Saroglitazar $4 \mathrm{mg}$ on non HDL-C as the primary endpoint and sd-LDL particles as a secondary endpoint in diabetic patients with dyslipidemia.

Methods: This study was a 24 weeks, prospective, multicentre, single arm study conducted in 104 patients with diabetic dyslipidemia ( $\mathrm{TG} \geq 200 \mathrm{mg} / \mathrm{dL}$ ) inadequately controlled with diet, exercise, and statins. It was conducted from April 2015 to November 2017 at three Indian centres. All the selected patients were given Saroglitazar $4 \mathrm{mg}$ once daily before breakfast for 24 weeks. Efficacy evaluations of non HDL-C (calculated as Total Cholesterol (TC) minus HDL-C) (primary endpoint) and other lipid parameters (sd-LDL particles, TC, TG, HDL-C) and glycemic parameters (glycosylated hemoglobin ( $\mathrm{HbA1c}$ ), fasting plasma glucose (FPG)) were conducted after 24 weeks and compared to the baseline levels.

Results: Total 104 patients ( $22 \%$ female) with mean age of $59.1 \pm 11.4$ years were enrolled in this study. In the perprotocol population, there was a significant reduction in non HDL-C (from $142.3 \pm 59.3 \mathrm{mg} / \mathrm{dL}$ (baseline) to $109.9 \pm$ $45.5 \mathrm{mg} / \mathrm{dL}$ (week-24); p<0.0001) and sd-LDL (from $32.5 \pm 11.3 \mathrm{mg} / \mathrm{dL}$ (baseline) to $25.9 \pm 11.8 \mathrm{mg} / \mathrm{dL}$ (week-24); $\mathrm{p}<0.0001)$. There was a significant reduction in TG, TC, HbA1c, and FPG with a significant increase in HDL-C at week-24 from baseline levels ( $\mathrm{p}<0.05)$.

Conclusion: Saroglitazar effectively reduces non HDL-C and sd-LDL particles in patients with diabetic dyslipidemia. Keywords: Diabetic dyslipidemia; Saroglitazar; Dual peroxisome proliferator activated receptor agonist; non HDL-C; SD-LDL particles; TG, HDL-C; HbA1c; FPG
\end{abstract}

\footnotetext{
*Corresponding author: Dr. Upendra Kaul MD, DM, FCSI, FSCAI, FAPSIC, FACC, FAMS, Batra Hospital and Medical Research Centre 1, Tughlakabad Institutional Area, Mehrauli Badarpur Road, New Delhi-110062, India, Tel: 011-29958747, 29902001; Mob: +91 9811150518; E-mail: kaul.upendra@gmail.com
}

Received date: January 30, 2019; Accepted date: February 15, 2019; Published date: February 23, 2019

Citation: Kaul U, Arambam P, Kachru R, Bhatia V, Diana Y, Diana Y, et al. (2019) A Prospective, Multicentre, Single Arm Clinical Study to Evaluate the Effect of Saroglitazar on Non High-Density Lipoprotein Cholesterol in Patients with Diabetic Dyslipidemia Inadequately Controlled with Diet, Exercise, and Statin-The GLIDDER Study. J Diabetes Metab 10:819. doi: 10.35248/2155-6156.19.10.819

Copyright: (C) 2019 Kaul U, et al. This is an open-access article distributed under the terms of the Creative Commons Attribution License, which permits unrestricted use, distribution, and reproduction in any medium, provided the original author and source are credited. 


\section{INTRODUCTION}

Cardiovascular diseases (CVDs) are the leading causes of morbidity and mortality globally and incidence of CVDs is rising rapidly, particularly in low-income and middle-income countries [1]. Diabetes and dyslipidemia are known risk factors for CVDs [1,2]. Indians have a high prevalence of diabetes and dyslipidemia, predisposing them to a higher risk for developing CVDs [2-4].

Dyslipidemia in type 2 diabetes mellitus (T2DM), also known as diabetic dyslipidemia, is characterised by increased triglyceride (TG), increased proportion of small dense low-density lipoprotein (sd-LDL) particles and decreased high-density lipoprotein cholesterol (HDL-C) [5,6]. Sd-LDL particles are more atherogenic compared to large buoyant LDL (lb-LDL) particles [6]. Additionally, high sd-LDL particles are strongly associated with high TG and low HDL-C and thus increase the risk for CVDs even when LDL-cholesterol (LDL-C) is at optimal levels [5-9]. Moreover, insulin resistance in T2DM can increase TG and sd-LDL levels, thus increasing the risk for CVDs [9-11].

Despite attaining the guideline-recommended LDL-C goals, dyslipidemic patients remain at a high residual risk for developing CVDs and this risk could be higher in dyslipidemic patients with T2DM [12,13]. Non HDL-C is measured as total cholesterol (TC) minus HDL-C and represents all the atherogenic cholesterol particles [14]. Non HDL-C could explain some of the residual risk for future CVDs [14]. Thus, treatment targeting non HDL-C is grounded in a more holistic principle of management of dyslipidemia compared to treatment targeting LDL-C $[14,15]$.

Saroglitazar is a novel peroxisome proliferator activated receptor (PPAR) $a / \gamma$ agonist approved in India for the management of diabetic dyslipidemia and hypertriglyceridemia in T2DM not controlled by statins alone $[16,17]$. PPAR- a agonism leads to activation of lipoprotein lipase and induces decrease in TG, while PPAR- $\gamma$ agonism induces decrease in insulin resistance and control of glycemic parameters, which could also lead to a decrease in TG [16-18]. Thus, Saroglitazar could also decrease sdLDL particles and non HDL-C $[16,18]$. Saroglitazar has been approved at a dose of $4 \mathrm{mg}$ once daily for oral administration and is marketed as LIPAGLYN ${ }^{\text {TM }}$ by Zydus Discovery (Cadila Healthcare Limited) in India since 2013 [16,17].

The effect of Saroglitazar on TG (as a primary endpoint) has been well established in clinical trials in patients with T2DM with hypertriglyceridemia not controlled by statins alone and in patients with diabetic dyslipidemia, but the effects of Saroglitazar on non HDL-C (as a primary endpoint) and sd-LDL particles (as a study endpoint) have not been evaluated [19-21].

\section{METHODS}

\section{Study design and participants}

The GLIDDER study was a prospective, multicentre, single arm clinical study to evaluate the effect of Saroglitazar $4 \mathrm{mg}$ once daily on non HDL-C (as a primary endpoint) in patients with diabetic dyslipidemia inadequately controlled with diet, exercise, and statins. This study was conducted from April 2015 to November 2017 at the following three centres in India: (i) Fortis Escorts Heart Institute \& Research Centre, Okhla Road, New Delhi; (ii) Fortis Hospital, Vasant Kunj, New Delhi; and (iii) Fortis Hospital, Noida, Uttar Pradesh. This study was approved by the independent ethics committee (IEC) at Fortis Escorts Heart Institute \& Research Centre, New Delhi and was registered with the Clinical Trial Registry of India (CTRI/ 2016/08/007126). It was conducted in accordance with the International Conference on Harmonisation (ICH)-Good Clinical Practice (GCP) guidelines, the ethical principles of Declaration of Helsinki, the GCP guidelines issued by Central Drugs Standard Control Organization and the ethical guidelines for biomedical research on human subjects, issued by Indian Council of Medical Research.

Patients aged $>18$ years with T2DM and TG $\geq 200 \mathrm{mg} / \mathrm{dL}$ after diet, exercise, and stable statin therapy for at least 3 months were selected. Patients were excluded if they were receiving insulin, glitazones, glitazar, or lipid-modifying therapy (e.g., fenofibrate) other than statins. Patients suffering from type 1 diabetes, diabetic complications such as diabetic nephropathy, diabetic ketoacidosis, diabetic coma, retinopathy, neuropathy or foot ulcers, or uncontrolled hypertension were also excluded. Patients with a history of unstable angina, acute myocardial infarction within the last 3 months, heart failure classified as New York Heart Association Class III-IV, arrhythmia, or Torsades de pointes were also excluded. Patients with uncontrolled thyroid disorders, gallstones, impaired liver function (demonstrated by aspartate aminotransferase and alanine aminotransferase $\geq 2.5$ times the upper normal limit [UNL] or bilirubin $\geq 2$ times the UNL), impaired renal function (demonstrated by serum creatinine $>1.5 \mathrm{mg} / \mathrm{dL}$ ), myopathies or active muscle diseases were also excluded. Patients suffering from tuberculosis, human immunodeficiency virus infection or malignancy were also excluded. Patients with history of alcohol and/or drug abuse or history of allergy, sensitivity or intolerance to the study drug and their formulation ingredients were also excluded. Patients with history of $\geq 5 \%$ weight change due to unknown reason within the last 6 months were also excluded. Patients who have participated in any other clinical trial within the last 3 months at the time of enrolment were also excluded. Females were excluded if they were pregnant or breast feeding or had initiated hormonal treatment (e.g., hormonal contraceptive, hormone replacement therapy) within the last 3 months. Each patient provided written informed consent prior to participating in this study.

Table 1: Study Plan.

Visit 1

(Screening Visit 2 Visit 3

Activity

and (Week (Week

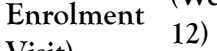

24)

(Week 0)

Informed consent $\sqrt{ }$ 


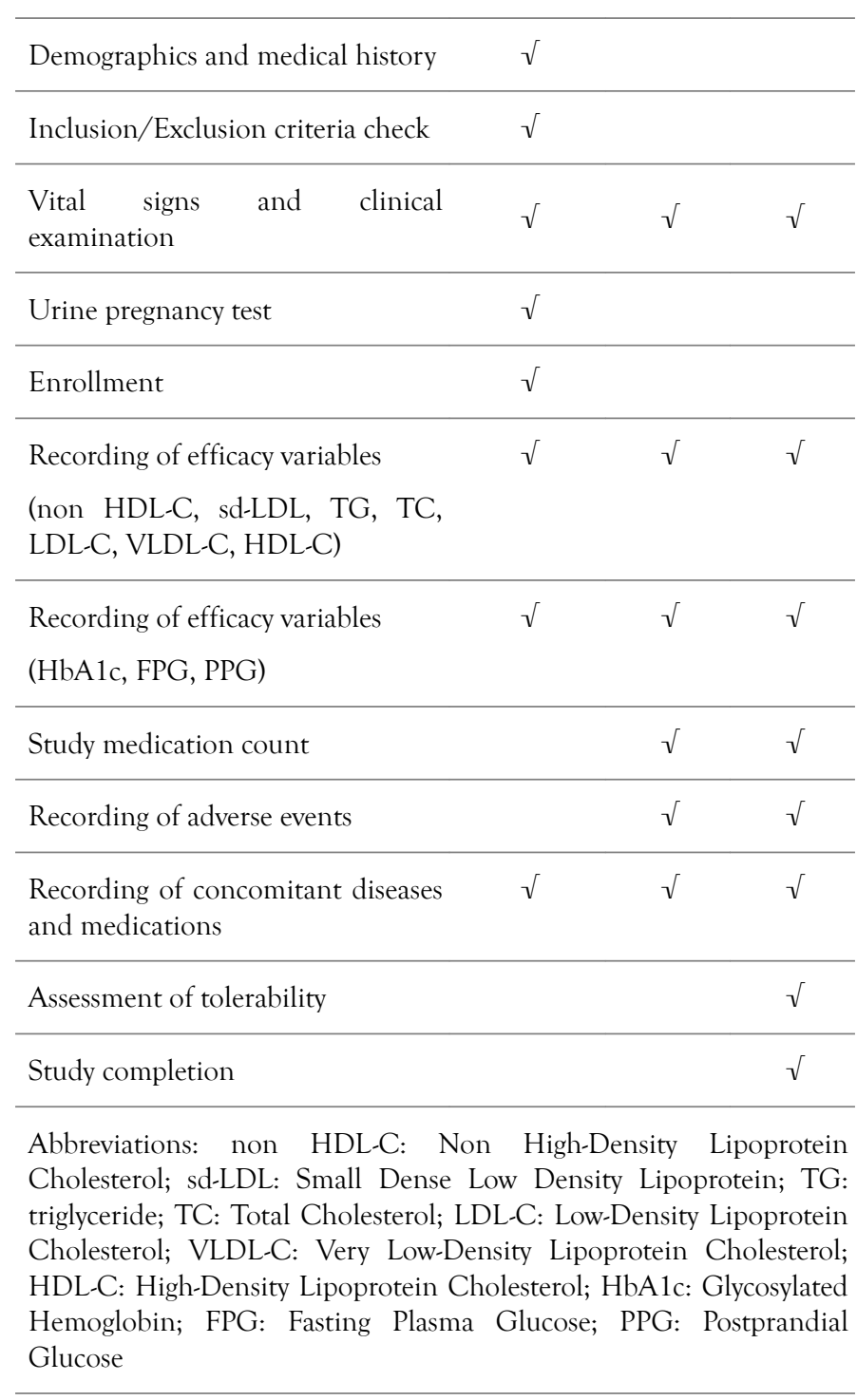

\section{Study protocol}

Patients were selected from the real-world clinical practice. Patients with an established diagnosis of T2DM with TG $\geq 200$ $\mathrm{mg} / \mathrm{dL}$ were evaluated as per the selection criteria. Eligible patients received treatment with Saroglitazar $4 \mathrm{mg}$ tablets once daily before breakfast for 24 weeks. The study medications were dispensed to the enrolled patients at week 0 (enrollment visit) and week-12 and compliance was verified by examination of the tablet containers and tablets count at week-12 and week-24 (Table 1). The patients were followed-up on an outpatient basis for the total study duration of 24 weeks. The enrolled patients were instructed to continue their existing diet, exercise and pharmacotherapy (antidiabetic drugs and statins) throughout the study period without any modification in the dose at the time of enrolment. Lipid parameters such as TG, TC, HDL-C, non HDL-C, LDL-C, sd-LDL, very LDL-C (VLDL-C), and glycemic parameters such as Glycosylated Hemoglobin (HbA1c), Fasting Plasma Glucose (FPG), Postprandial Plasma Glucose (PPG) were measured at the time of screening and enrolment at week-0 (baseline), week-12 ( $1^{\text {st }}$ follow-up visit) and week-24 ( $2^{\text {nd }}$ follow-up visit/end of the study). Routine physical examination was carried out at all the study visits. Adverse Events (AEs) were recorded and assessed by the investigators. The association of the AEs with the study medication was ascertained by the WHO-UMC criteria [22]. All laboratory investigations were performed at SRL Diagnostics (https://www.srlworld.com/) at the individual study centres. The laboratory investigation for sdLDL particles was done by spectrophotometric enzymatic method.

The primary efficacy endpoint was the mean change in non HDL-C level at week-12 and week-24 compared to baseline (week-0) value. The secondary efficacy endpoints were: (i) the mean change in TG, TC, HDL-C, LDL-C, sd-LDL, VLDL-C, non HDL-C/HDL-C ratio at week-12 and week-24 compared to baseline values; (ii) the mean change in $\mathrm{HbA1c}$, FPG, and PPG at week-12 and week-24 compared to the baseline values.

\section{Statistical analysis}

Statistical analysis was conducted using SAS software (version 9.4; SAS Institute Inc., USA). A sample size of 98 subjects was required to achieve a $95 \%$ power and to detect a mean difference of $15.0 \mathrm{mg} / \mathrm{dL}$ in non HDL-C at week-24 from baseline value with a standard deviation (SD) of differences of 40.0 and with a significance level (alpha) of $5 \%$ using a two sided paired t-test. Considering a dropout rate of $10 \%$, a total of 109 subjects were planned to be enrolled in this study.

Data has been presented as mean \pm SD or number (percentage). The primary and secondary efficacy endpoints were assessed by paired t-test and $\mathrm{p}<0.05$ was considered as a statistically significant $\mathrm{p}$ value. For efficacy analysis, modified Intention-ToTreat (mITT) analysis and Per-Protocol (PP) analysis were performed, where the PP analysis was considered as definitive, while the mITT analysis was considered as supportive. The PP population included all the enrolled patients who completed the study as per the study protocol including minor deviations. The mITT population included all the enrolled patients who completed at least one post enrolment follow-up visit with efficacy endpoints assessments. Last Observation Carried Forward (LOCF) method was used to impute missing data for the mITT population. The safety population included all the enrolled patients who have taken at least one dose of study medication and have completed at least one post enrolment follow-up visit with safety assessment.

\section{RESULTS}

\section{Demographics and patient disposition}

Total 104 patients $(22 \%$ female) with a mean age of $59.1 \pm 11.4$ years, mean weight of $73.2 \pm 11.2 \mathrm{~kg}$, and mean Body Mass Index (BMI) of $27.4 \pm 3.9 \mathrm{~kg} / \mathrm{m}^{2}$ were enrolled in this study (Table 2).

Table 2: Baseline Characteristics of Selected Patients.

$$
\text { Total patients }(\mathbf{n})
$$

104

\begin{tabular}{lc}
\hline Age (years), $(\mathrm{M} \pm \mathrm{SD})$ & $59.1 \pm 11.4$ \\
\hline Female, n $(\%)$ & $23(22.1 \%)$ \\
\hline
\end{tabular}




\begin{tabular}{lc}
\hline Male, $\mathrm{n}(\%)$ & $81(77.9 \%)$ \\
\hline Height $(\mathrm{cm}), \mathrm{M} \pm \mathrm{SD}$ & $164.0 \pm 9.0$ \\
\hline Weight $(\mathrm{kg}), \mathrm{M} \pm \mathrm{SD}$ & $73.2 \pm 11.2$ \\
\hline $\mathrm{BMI}\left(\mathrm{kg} / \mathrm{m}^{2}\right), \mathrm{M} \pm \mathrm{SD}$ & $27.4 \pm 3.9$ \\
\hline Pulse rate (bpm), M $\pm \mathrm{SD}$ & $76.2 \pm 8.8$ \\
\hline Blood pressure (mm Hg) & $132.0 \pm 16.0$ \\
\hline Systolic, M $\pm \mathrm{SD}$ & $79.0 \pm 9.0$ \\
\hline Diastolic, M $\pm \mathrm{SD}$ & \\
\hline Medical history & $77(74.0 \%)$ \\
\hline Hypertension, $\mathrm{n}(\%)$ & $6(5.8 \%)$ \\
\hline Obesity, n (\%) & $4(3.8 \%)$ \\
\hline Hypothyroidism, n (\%) & $26(25.0 \%)$ \\
\hline Coronary artery disease, $\mathrm{n}(\%)$ & $5(4.8 \%)$ \\
\hline Left ventricular dysfunction, $\mathrm{n}(\%)$ & \\
\hline Baseline & \\
\hline
\end{tabular}

\section{Baseline medications, $\mathrm{n}(\%)$}

\begin{tabular}{ll}
\hline High dose Statin* & $29(27.9 \%)$ \\
\hline Acetylsalicylic acid (aspirin) & $31(29.8 \%)$ \\
\hline Clopidegrol & $18(17.3 \%)$ \\
\hline Beta-Blocker & $37(35.6 \%)$ \\
\hline Other anti-hypertensive & $54(51.9 \%)$ \\
\hline
\end{tabular}

\section{Lipid Parameters, $\mathrm{M} \pm \mathrm{SD}$}

\begin{tabular}{lc}
\hline Non HDL-C $(\mathrm{mg} / \mathrm{dL})$ & $140.0 \pm 55.0$ \\
\hline $\mathrm{TG}(\mathrm{mg} / \mathrm{dL})$ & $357.0 \pm 332.0$ \\
\hline $\mathrm{TC}(\mathrm{mg} / \mathrm{dL})$ & $176.0 \pm 62.0$ \\
\hline $\mathrm{HDL}-\mathrm{C}(\mathrm{mg} / \mathrm{dL})$ & $37.5 \pm 16.6$ \\
\hline $\mathrm{LDL}-\mathrm{C}(\mathrm{mg} / \mathrm{dL})$ & $91.0 \pm 37.0$ \\
\hline sd-LDL $(\mathrm{mg} / \mathrm{dL})$ & $32.9 \pm 11.5$ \\
\hline VLDL-C $(\mathrm{mg} / \mathrm{dL})$ & $54.0 \pm 20.4$ \\
\hline
\end{tabular}

\section{Glycemic Parameters, $\mathrm{M} \pm \mathrm{SD}$}

HbA1c (\%) $\quad 7.9 \pm 1.6$

\begin{tabular}{lc}
\hline FPG $(\mathrm{mg} / \mathrm{dL})$ & $156.0 \pm 52.0$ \\
\hline $\mathrm{PPG}(\mathrm{mg} / \mathrm{dL})$ & $223.0 \pm 77.0$ \\
\hline
\end{tabular}

*All 104 patients were on stable statin therapy and 29 out of 104 patients were on high dose statin (atleast $20 \mathrm{mg}$ of Rosuvastatin or 40 mg of Atorvastatin)

Abbreviations: M: Mean; SD: Standard Deviation; n: number; BMI: Body Mass Index; bpm: beats per minute; mmHg: millimeter of Mercury; mg: milligram; dL: deciLitre; non HDL-C: non HighDensity Lipoprotein Cholesterol; sd-LDL: small dense Low Density Lipoprotein; TG: Triglyceride; TC: Total Cholesterol; LDL-C: LowDensity Lipoprotein Cholesterol; VLDL-C: Very Low-Density Lipoprotein Cholesterol; HDL-C: High-Density Lipoprotein Cholesterol; HbA1c: Glycosylated Hemoglobin; FPG: Fasting Plasma Glucose; PPG: Postprandial Glucose

Total 77 (74\%) patients had hypertension and 26 (25\%) patients had coronary artery disease at the time of enrolment in the study (Table 2). All the patients were on stable statin therapy throughout the study period. Total 29 (28\%) patients were on high dose statins, 37 (36\%) were on beta-blockers, and 54 (52\%) were on other anti-hypertensives (Table 2). In total, 20 patients discontinued the study: 2 patients voluntarily withdrawn, 17 patients lost to follow-up, and 1 subject due to major protocol violation. One patient died during the study. Due to not meeting the eligibility criteria, one patient was considered only for the mITT analysis but not for the PP analysis. In total, 81 patients qualified for the PP analysis, 100 patients qualified for the mITT analysis, and 100 patients qualified for the safety analysis.

\section{Efficacy analysis}

In the PP population, non HDL-C level significantly reduced from $142.3 \pm 59.3 \mathrm{mg} / \mathrm{dL}$ at baseline to $109.6 \pm 33.9 \mathrm{mg} / \mathrm{dL}$ at week-12 $(\mathrm{p}<0.0001)$ and $109.9 \pm 45.5 \mathrm{mg} / \mathrm{dL}$ at week-24 ( $<<0.0001)$ (Table 3). In the PP population, sd-LDL level also significantly reduced from $32.5 \pm 11.3 \mathrm{mg} / \mathrm{dL}$ at baseline to 26.3 $\pm 9.5 \mathrm{mg} / \mathrm{dL}$ at week $-12(\mathrm{p}<0.0001)$ and $25.9 \pm 11.8 \mathrm{mg} / \mathrm{dL}$ at week-24 ( $<<0.0001)$ (Table 3$)$. In the PP population, TG level also significantly reduced from $371.4 \pm 368.3 \mathrm{mg} / \mathrm{dL}$ at baseline to $241.6 \pm 298.8 \mathrm{mg} / \mathrm{dL}$ at week-12 (p<0.0001) and $239.1 \pm$ $431.5 \mathrm{mg} / \mathrm{dL}$ at week-24 ( $=0.0004)$ (Table 3). In the PP population, HDL-C level also significantly increased from $37.3 \pm$ $18.4 \mathrm{mg} / \mathrm{dL}$ at baseline to $42.9 \pm 16.5 \mathrm{mg} / \mathrm{dL}$ at week-12 $(\mathrm{p}=0.0007)$ and $43.4 \pm 15.6 \mathrm{mg} / \mathrm{dL}$ at week-24 ( $\mathrm{p}=0.0002)$ (Table 3). Similarly, the values of TC, VLDL-C, and non HDL-C/ HDL-C ratio significantly reduced from baseline to week-12 and week-24 in the PP population $(p<0.05)$ (Table 3). However, the value of LDL-C was not significantly reduced from baseline to week-24 in the PP population (Table 3).

Table 3: Change in Efficacy Outcomes at Week-12 and Week-24 from Baseline in the Per-Protocol Population (Number of Patients=81). 


\begin{tabular}{|c|c|c|c|c|c|}
\hline Efficacy Outcomes & Baseline $\mathrm{M} \pm \mathrm{SD}$ & Week-12 Visit $M \pm S D$ & p value* & Week-24 Visit $\mathrm{M} \pm \mathrm{SD}$ & p value\# \\
\hline Non HDL-C (mg/dL) & $142.3 \pm 59.3$ & $109.6 \pm 33.9$ & $<0.0001$ & $109.9 \pm 45.5$ & $<0.0001$ \\
\hline $\mathrm{TG}(\mathrm{mg} / \mathrm{dL})$ & $371.4 \pm 368.3$ & $241.6 \pm 298.8$ & $<0.0001$ & $239.1 \pm 431.5$ & 0.0004 \\
\hline $\mathrm{TC}(\mathrm{mg} / \mathrm{dL})$ & $178.7 \pm 67.8$ & $153.3 \pm 38.6$ & $<0.0001$ & $153.6 \pm 49.4$ & 0.0002 \\
\hline HDL-C (mg/dL) & $37.3 \pm 18.4$ & $42.9 \pm 16.5$ & 0.0007 & $43.4 \pm 15.6$ & 0.0002 \\
\hline LDL-C (mg/dL) & $91.9 \pm 39.5$ & $83.9 \pm 26.7$ & 0.0407 & $84.9 \pm 25.9$ & 0.1112 \\
\hline $\mathrm{sd}-\mathrm{LDL}(\mathrm{mg} / \mathrm{dL})$ & $32.5 \pm 11.3$ & $26.3 \pm 9.5$ & $<0.0001$ & $25.9 \pm 11.8$ & $<0.0001$ \\
\hline VLDL-C (mg/dL) & $56.1 \pm 21.8$ & $36.7 \pm 21.3$ & $<0.0001$ & $39.6 \pm 31.0$ & $<0.0001$ \\
\hline non HDL-C/HDL-C^^ & $2.2 \pm 0.6$ & $1.5 \pm 0.7$ & $<0.0001$ & $1.4 \pm 0.7$ & $<0.0001$ \\
\hline HbA1c (\%) & $8.1 \pm 1.7$ & $7.2 \pm 1.1$ & $<0.0001$ & $6.9 \pm 0.7$ & $<0.0001$ \\
\hline $\mathrm{FPG}(\mathrm{mg} / \mathrm{dL})$ & $159.7 \pm 54.1$ & $134.2 \pm 41.7$ & $<0.0001$ & $125.8 \pm 33.2$ & $<0.0001$ \\
\hline PPG (mg/dL) & $227.3 \pm 80.8$ & $191.3 \pm 60.9$ & $<0.0001$ & $179.2 \pm 57.2$ & $<0.0001$ \\
\hline
\end{tabular}

*p value belongs to paired t-test to determine change from baseline to week-12

\# $\mathrm{p}$ value belongs to paired t-test to determine change from baseline to week-24

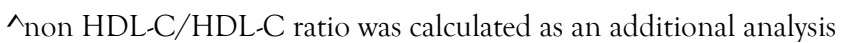

Abbreviations: non HDL-C: Non High-Density Lipoprotein Cholesterol; sd-LDL: Small Dense Low Density Lipoprotein; TG: Triglyceride; TC: Total Cholesterol; LDL-C: Low-Density Lipoprotein Cholesterol; VLDL-C: Very Low-Density Lipoprotein Cholesterol; HDL-C: High-Density Lipoprotein Cholesterol; HbA1c: Glycosylated Hemoglobin; FPG: Fasting Plasma Glucose; PPG: Postprandial Plasma Glucose; M: Mean; SD: Standard Deviation; mg: Milligram; dL: Decilitre

In the PP population, HbA1c (\%) significantly reduced from 8.1 \pm 1.7 at baseline to $7.2 \pm 1.1$ at week-12 $(\mathrm{p}<0.0001)$ and $6.9 \pm 0.7$ at week-24 ( $<<0.0001)$ (Table 3). In the PP population, FPG level significantly reduced from $159.7 \pm 54.1 \mathrm{mg} / \mathrm{dL}$ at baseline to $134.2 \pm 41.7 \mathrm{mg} / \mathrm{dL}$ at week-12 $(\mathrm{p}<0.0001)$ and $125.8 \pm 33.2$ $\mathrm{mg} / \mathrm{dL}$ at week-24 ( $<00.0001)$ (Table 3$)$. In the PP population,
PPG level significantly reduced from $227.3 \pm 80.8 \mathrm{mg} / \mathrm{dL}$ at baseline to $191.3 \pm 60.9 \mathrm{mg} / \mathrm{dL}$ at week-12 $(\mathrm{p}<0.0001)$ and 179.2 $\pm 57.2 \mathrm{mg} / \mathrm{dL}$ at week-24 ( $<00.0001)$ (Table 3$)$. Similar results were observed for lipid parameters and glycemic parameters in the mITT population (Table 4).

Table 4: Change in Efficacy Outcomes at Week-12 and Week-24 from Baseline in the Modified Intention-To-Treat Population (Number of Patients=100).

\begin{tabular}{|c|c|c|c|c|c|}
\hline Efficacy Outcomes & Baseline $\mathrm{M} \pm \mathrm{SD}$ & Week-12 Visit $\mathrm{M} \pm \mathrm{SD}$ & p value* & $\begin{array}{l}\text { Week-24 Visit M } \pm \\
\text { SD }\end{array}$ & $\mathrm{p}$ value\# \\
\hline Non HDL-C (mg/dL) & $142.6 \pm 55.9$ & $111.6 \pm 33.5$ & $<0.0001$ & $111.7 \pm 42.7$ & $<0.0001$ \\
\hline $\mathrm{TG}(\mathrm{mg} / \mathrm{dL})$ & $366.7 \pm 340.4$ & $242.1 \pm 276.9$ & $<0.0001$ & $239.8 \pm 391.1$ & $<0.0001$ \\
\hline $\mathrm{TC}(\mathrm{mg} / \mathrm{dL})$ & $178.8 \pm 63.5$ & $153.2 \pm 36.4$ & $<0.0001$ & $153.5 \pm 45.6$ & $<0.0001$ \\
\hline HDL-C (mg/dL) & $37.8 \pm 16.9$ & $42.3 \pm 15.2$ & 0.0011 & $42.9 \pm 14.3$ & 0.0002 \\
\hline LDL-C (mg/dL) & $91.6 \pm 36.8$ & $85.5 \pm 28.0$ & 0.0682 & $85.5 \pm 27.5$ & 0.1091 \\
\hline sd-LDL (mg/dL) & $34.5 \pm 20.2$ & $27.2 \pm 9.1$ & 0.0002 & $26.4 \pm 11.2$ & $<0.0001$ \\
\hline
\end{tabular}




\begin{tabular}{|c|c|c|c|c|c|}
\hline VLDL-C (mg/dL) & $54.2 \pm 20.6$ & $38.2 \pm 24.7$ & $<0.0001$ & $41.3 \pm 31.8$ & $<0.0001$ \\
\hline non HDL-C/HDL- ${ }^{\wedge}$ & $2.2 \pm 0.6$ & $1.6 \pm 0.7$ & $<0.0001$ & $1.5 \pm 0.7$ & $<0.0001$ \\
\hline HbA1c (\%) & $8.0 \pm 1.7$ & $7.2 \pm 1.1$ & $<0.0001$ & $6.9 \pm 0.7$ & $<0.0001$ \\
\hline $\mathrm{FPG}(\mathrm{mg} / \mathrm{dL})$ & $158.4 \pm 52.0$ & $133.0 \pm 39.8$ & $<0.0001$ & $127.7 \pm 31.6$ & $<0.0001$ \\
\hline PPG (mg/dL) & $223.6 \pm 77.8$ & $190.5 \pm 58.6$ & $<0.0001$ & $183.5 \pm 54.8$ & $<0.0001$ \\
\hline
\end{tabular}

${ }^{*} \mathrm{p}$ value belongs to paired t-test to determine change from baseline to week-12

\# $\mathrm{p}$ value belongs to paired $\mathrm{t}$-test to determine change from baseline to week-24

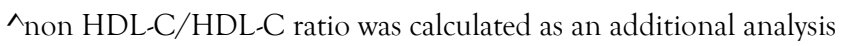

Abbreviations: non HDL-C: non High-Density Lipoprotein Cholesterol; sd-LDL: small dense Low Density Lipoprotein; TG: Triglyceride; TC: Total Cholesterol; LDL-C: Low-Density Lipoprotein Cholesterol; VLDL-C: Very Low-Density Lipoprotein Cholesterol; HDL-C: High-Density Lipoprotein Cholesterol; HbA1c: Glycosylated Hemoglobin; FPG: Fasting Plasma Glucose; PPG: Postprandial Plasma Glucose; M: Mean; SD: Standard Deviation; mg: Milligram; dL: Decilitre

\section{Safety analysis}

There was no significant change in weight $(\mathrm{kg})$ throughout the study period (baseline: $73.5 \pm 11.3 \mathrm{~kg}$; week-12: $73.2 \pm 10.6 \mathrm{~kg}$; week-24: $73.9 \pm 10.5 \mathrm{~kg})$. The reported AEs were burning sole $(1$ patient), occasional chest discomfort/chest pain (2 patients), hypoglycemia after first dosing (1 patient), and occasional suffocation (1 patient). None of the AEs were severe in nature. The occasional suffocation was related to Ticagrelor and it disappeared after changing Ticagrelor to Clopidogrel. Only hypoglycemia after first dosing was found to be drug induced. One patient died during the study period; however, the cause of death was sepsis and not related to Saroglitazar use.

\section{DISCUSSION AND CONCLUSION}

This study was a 24 weeks, multicenter, prospective, single arm clinical study to evaluate the effect of Saroglitazar $4 \mathrm{mg}$ once daily on non HDL-C (as a primary endpoint) in 104 patients with $\mathrm{T} 2 \mathrm{DM}$ and $\mathrm{TG} \geq 200 \mathrm{mg} / \mathrm{dL}$ inadequately controlled with diet, exercise, and statins. In this study, we observed a significant reduction in non HDL-C, sd-LDL, TG, TC, VLDL-C, non HDL-C/HDL-C ratio and significant increase in HDL-C from baseline to week-24 in both the PP and mITT populations. There was a non-significant reduction in LDL-C from baseline to week-24 in both the PP and IITT populations; however, LDL-C remained at the optimal level throughout the study period. Moreover, glycemic parameters such as HbA1c, FPG, and PPG were also significantly reduced from baseline to week-24 in both the PP and mITT populations. Further, Saroglitazar $4 \mathrm{mg}$ appeared to be safe during the study period without any significant change in the body weight or any significant AEs throughout the study period.

In this study, Saroglitazar favourably modulated the lipid and glucose profile without any significant AEs in patients with diabetic dyslipidemia. Saroglitazar could address the residual cardiovascular risk associated with non HDL-C [14,23]. The Emerging Risk Factors Collaboration (University of Cambridge,
UK) conducted a study of more than 300,000 people without initial vascular disease from 68 long-term prospective studies and found that non HDL-C was a strong predictor of coronary heart disease (CHD) (50\% increase in the risk) and ischemic stroke (12\% increase in the risk) [24]. The authors also found that non HDL-C/HDL-C ratio was also associated with a $50 \%$ increase in the risk of CHD [24]. Further, Saroglitazar could also address the cardiovascular risk associated with sd-LDL in patients with normal LDL-C levels [25]. Hoogeveen et al. conducted a prospective study among Atherosclerosis Risk in Communities (ARIC) study participants (11,419 men and women) to determine the association between sd-LDL and the risk for incident CHD over 11 years of the study period [25]. The authors found that in patients with low cardiovascular risk based on their LDL-C levels, sd-LDL was associated with a $61 \%$ increased risk for incident CHD (hazard ratio: 1.61; 95\% confidence interval: 1.04 to 2.49) [25]. Moreover, high TG could induce modifications in lipoproteins such as they increase sdLDL particles and decrease HDL-C [6-9]. Therefore, treatment targeting reduction of TG could also lead to shift of LDL-C morphology by reducing sd-LDL particles, making LDL-C less atherogenic, and reducing the risk for future CHD [6-9].

The results of this study are consistent with the mechanism of action of Saroglitazar. Saroglitazar is a novel dual PPAR agonist and has predominantly a PPAR- $a$ agonist action and a modest PPAR $-\gamma$ agonist action [16]. Through PPAR-a agonist action, Saroglitazar increases the hepatic oxidation of fatty acids and lowers the synthesis and secretion of TG [16]. Moreover, Saroglitazar increases lipolysis and removes TG-rich particles from plasma by activating lipoprotein lipase [16]. Further, Saroglitazar also reduces LDL-C and sd-LDL levels and increases HDL-C level [16]. Through PPAR- $\gamma$ agonist action, Saroglitazar increases insulin sensitivity in peripheral tissues and thereby increases glucose uptake, lowers blood glucose levels, and improves glycemic parameters [16].

The results of this study are also consistent with the results of the phase- 3 clinical trial of Saroglitazar in patients with diabetic 
dyslipidemia (PRESS V) [20]. PRESS V study was a 24 weeks, double-blind, parallel arm, phase 3 study conducted in India to evaluate the safety and efficacy of Saroglitazar $2 \mathrm{mg}$ and $4 \mathrm{mg}$ compared to Pioglitazone $45 \mathrm{mg}$ in T2DM patients with hypertriglyceridemia (TG>200 to $400 \mathrm{mg} / \mathrm{dL}$; HbA1c>7 to $9 \%$; BMI $>23 \mathrm{~kg} / \mathrm{m}^{2}$ ) [20]. In the PRESS V study, Saroglitazar $2 \mathrm{mg}$ and $4 \mathrm{mg}$ significantly reduced TG level by upto $45 \%$ from baseline [20]. There was also a significant decrease in LDL-C, VLDL-C, and TC with Saroglitazar $4 \mathrm{mg}$ [20].

This study has a few unique features. This is the first study to examine the effects of Saroglitazar $4 \mathrm{mg}$ on non HDL-C (as a primary endpoint) and sd-LDL particles (as a study endpoint) in patients with diabetic dyslipidemia. Moreover, patients were selected from the real-world clinical practice setup, which improves the generalizability of the study results to the real-world clinical practice. This study is limited by a small sample size of 104 patients. Moreover, there were 17 patients lost to follow-up in this study and we cannot confirm whether these patients were lost to follow-up due to some AEs or due to other personal reasons. Therefore, we cannot rule out the possibility of underreporting of AEs due to lost to follow-up in this study based on real-world clinical practice. Another potential limitation of this study is the short study duration of 24 weeks. Recently, Chatterjee et al. examined the effect of Saroglitazar $4 \mathrm{mg}$ in T2DM patients with hypertriglyceridemia $(>150 \mathrm{mg} / \mathrm{dL})$ in a 58 weeks observational study based on real-world clinical practice in India [26]. The authors found significant reduction in non HDL-C from $140.1 \pm 55.4(\mathrm{mg} / \mathrm{dL})$ at baseline to $104.5 \pm 49.7$ $(\mathrm{mg} / \mathrm{dL})$ at week-58 (reduction of $35.6 \pm 58.9(\mathrm{mg} / \mathrm{dL}) ; \mathrm{p}<0.001)$ and TG from $319.9 \pm 178.8(\mathrm{mg} / \mathrm{dL})$ at baseline to $174.0 \pm 113.6$ $(\mathrm{mg} / \mathrm{dL})$ at week-58 (reduction of $145.8 \pm 186.6(\mathrm{mg} / \mathrm{dL})$; $\mathrm{p}<0.001$ ) [26]. Moreover, HbA1c (\%) was also significantly reduced from $7.9 \pm 1.5$ at baseline to $7.3 \pm 1.4$ at week-58 (reduction of $0.6 \pm 1.4 ; \mathrm{p}<0.001$ ) [26]. The study results of Chatterjee et al. are encouraging to support the long-term benefits from Saroglitazar $4 \mathrm{mg}$ in T2DM patients with hypertriglyceridemia [26].

Overall, Saroglitazar $4 \mathrm{mg}$ was effective and well tolerated in patients with diabetic dyslipidemia. Considering the favourable effects on non HDL-C, sd-LDL, and other lipid parameters and glycemic parameters in this study, Saroglitazar $4 \mathrm{mg}$ could potentially reduce the cardiovascular risk in patients with diabetic dyslipidemia.

\section{DISCLOSURES}

All investigators of this study contributed to study design, data collection, interpretation of the study results, and manuscript writing, whereas Dr Mitesh Shah and Ms Krupi Parmar contributed to statistical analysis, interpretation of the study results, and manuscript writing.

\section{ACKNOWLEDGMENT}

The GLIDDER study was presented at the 78th Scientific Sessions, American Diabetes Association, June 22-26, 2018, Orlando, USA. The poster presentation number was 38-LB at Late Breaking Poster Session.

\section{DECLARATION OF CONFLICTING INTERESTS}

The authors declared no potential conflicts of interest with respect to the research, authorship, and/or publication of this study. Dr Ashok Jaiswal is an employee of Cadila Healthcare Limited, Ahmedabad, India. Dr Mitesh Shah and Ms Krupi Parmar are employees of Zydus Research Centre, Cadila Healthcare Limited, Ahmedabad, India.

\section{REFERENCES}

1. Yusuf S, Hawken S, Ôunpuu S, Dans T, Avezum A, Lanas F. Effect of potentially modifiable risk factors associated with myocardial infarction in 52 countries (the INTERHEART study): case-control study. Lancet. 2004;364:937-952.

2. Joshi SR, Anjana RM, Deepa M, Pradeepa R, Bhansali A, Dhandania VK, et al. Prevalence of dyslipidemia in urban and rural India: the ICMR-INDIAB study. PloS One. 2014;9:e96808.

3. Kaveeshwar SA, Cornwall J. Diabetes mellitus in india. Australas Med J. 2014;7:45.

4. Joshi SR, Saboo B, Vadivale M, Dani SI, Mithal A, Kaul U, et al.Prevalence of diagnosed and undiagnosed diabetes and hypertension in India-results from the Screening India's Twin Epidemic (SITE) study. Diabetes Technol Ther. 2012;14:8-15.

5. Solano MP, Goldberg RB.Lipid management in type 2 diabetes. Clin Diabetes. 2006;24:27-32.

6. Grundy S. Small LDL, Atherogenic Dyslipidemia, and the Metabolic Syndrome. Circulation. 1997;95:1-4.

7. Carmena R, Duriez P, Fruchart JC. Atherogenic lipoprotein particles in atherosclerosis. Circulation. 2004;109:II12-II17.

8. Musunuru K. Atherogenic Dyslipidemia: Cardiovascular Risk and Dietary Intervention. Lipids. 2010;45:907-914.

9. Austin MA, King MC, Vranizan KM, Krauss RM. Atherogenic lipoprotein phenotype. A proposed genetic marker for coronary heart disease risk. Circulation. 1990;82:495-506.

10. DeFronzo RA. Insulin resistance, lipotoxicity, type 2 diabetes and atherosclerosis: the missing links. The Claude Bernard Lecture 2009. Diabetologia. 2010;53:1270-1287.

11. Ginsberg HN. Insulin resistance and cardiovascular disease. J Clin Invest. 2000;106:453-458.

12. Cannon CP, Braunwald E, McCabe CH, Rader DJ, Rouleau JL, Belder R, et al. Intensive versus moderate lipid lowering with statins after acute coronary syndromes. N Engl J Med. 2004;350:1495-1504.

13. Sirimarco G, Labreuche J, Bruckert E, Goldstein LB, Fox KM, Rothwell PM, et al. Atherogenic dyslipidemia and residual cardiovascular risk in statin-treated patients. Stroke. 2014;45:1429-1436.

14. Virani SS. Non-HDL cholesterol as a metric of good quality of care: opportunities and challenges. Tex Heart Inst J. 2011;38:160-162.

15. Expert Panel on Detection, Evaluation, and Treatment of High Blood Cholesterol in Adults. Executive Summary of the Third Report of the National Cholesterol Education Program (NCEP) Expert Panel on Detection, Evaluation, and Treatment of High Blood Cholesterol in Adults (Adult Treatment Panel III). JAMA: the journal of the American Medical Association. 2001;285:2486-2497.

16. Sosale A, Saboo B, Sosale B. Saroglitazar for the treatment of hypertrig-lyceridemia in patients with type 2 diabetes: current evidence. Diabetes Metab Syndr Obes. 2015;8:189.

17. Agrawal R. The first approved agent in the Glitazar's class: saroglitazar. Curr Drug Targ. 2014;15:151-155. 
18. Campbell IW. The clinical significance of PPAR gamma agonism. Curr Mol Med. 2005;5:349-363.

19. Jani RH, Kansagra K, Jain MR, Patel H. Pharmacokinetics, safety, and tolerability of saroglitazar (ZYH1), a predominantly PPAR a agonist with moderate PPAR $\gamma$ agonist activity in healthy human subjects. Clin Drug Investig. 2013;33:809-816.

20. Pai V, Paneerselvam A, Mukhopadhyay S, Bhansali A, Kamath D, et al. A multicenter, prospective, randomized, double-blind study to evaluate the safety and efficacy of saroglitazar 2 and $4 \mathrm{mg}$ compared to pioglitazone $45 \mathrm{mg}$ in diabetic dyslipidemia (PRESS V). J Diabetes Sci Technol. 2014;8:132-141.

21. Jani RH, Pai V, Jha P, Jariwala G, Mukhopadhyay S, Bhansali A, et al. A multicenter, prospective, randomized, double-blind study to evaluate the safety and efficacy of Saroglitazar 2 and $4 \mathrm{mg}$ compared with placebo in type 2 diabetes mellitus patients having hypertriglyceridemia not controlled with atorvastatin therapy (PRESS VI). Diabetes Technol Ther. 2014;16:63-71.
22. The use of the WHO-UMC system for standardised case causality assessment

23. Fruchart JC, Sacks F, Hermans MP, Assmann G, Brown WV, Ceska R, et al. The Residual Risk Reduction Initiative: a call to action to reduce residual vascular risk in patients with dyslipidemia. Am J Cardiol. 2008;102:1K-34K

24. Emerging Risk Factors Collaboration. Major lipids, apolipoproteins, and risk of vascular disease. JAMA. 2009;302:1993-2000.

25. Hoogeveen RC, Gaubatz JW, Sun W, Dodge RC, Crosby JR, Jiang J, et al. Small dense low-density lipoprotein-cholesterol concentrations predict risk for coronary heart disease: the Atherosclerosis Risk In Communities (ARIC) study. Arterioscler Thromb Vasc Biol. 2014;34:1069-1077.

26. Chatterjee S, Majumder A, Ray S Bhattacharjee K. Observational Study of Saroglitazar on Metabolic Parameters in Indian Patients with Diabetic Dyslipidaemia-A Fifty Eight Weeks of Clinical Experience. Diabetes Obes Int J. 2018;3:000180. 